\title{
O ritmo visual nos Cartemas de Aloísio Magalhães
}

\author{
Airton Jordani Jardim Filho \\ Sandra Regina Ramalho e Oliveira \\ UDESC - Universidade do Estado de Santa Catarina
}

\section{Resumo}

O presente artigo apresenta a análise de um cartema de Aloísio Magalhães - proeminente artista visual e desenhista industrial brasileiro - com foco no ritmo visual, fundamento estético-visual gerador da dinâmica e da estesia provocadas pelos cartemas. Buscou-se, em um primeiro momento, o conceito de ritmo visual em diferentes áreas do conhecimento e distintas bases teóricas. Num segundo momento, partiu-se para uma análise formal sintética, com o objetivo de identificar a macroestrutura da imagem visual e, consequentemente seus elementos constitutivos.

Palavras-chave: artes visuais, ritmo, cartemas, Aloísio Magalhães.

\section{Abstract}

This article presents an analysis of a cartema by Aloísio Magalhães - prominent Brazilian visual artist and industrial designer - focused on the visual rhythm, aesthetic and visual principles, esthesia and dynamic generator, caused by cartemas. At first, the concept of visual rhythm in different areas of knowledge and different theoretical bases is presented. Secondly, a synthetic formal analysis is made in order to identify the macro-structure of the visual image and consequently its constituent elements.

Keywords: visual arts, rhythm, cartemas, Aloísio Magalhães.

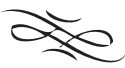

\section{Entre as Artes Visuais e o Design Gráfico}

Inegável é a contribuição de Aloísio Magalhães para a expansão e consolidação do Design no Brasil ${ }^{1}$, não só como uma atividade profissional em si, mas, também, como $\alpha<\infty<\infty<\infty<\infty<\infty<\infty<\infty<\infty<\infty<\infty<\infty<$

1 Tal reconhecimento pode ser atestado pelo Decreto Presidencial de 19 de outubro de 1998, que institui a data de 5 de novembro - aniversário de Aloisio Magalhães - como o Dia Nacional do Design (Presidência da República, 2016). 
área do conhecimento - já há algum tempo reconhecida pelas estruturas da educação formal no país. Sua faceta menos (re)conhecida, tanto no meio acadêmico, quanto profissional - a de artista visual -, no entanto, foi igualmente inovadora no cenário cultural brasileiro. Ainda muito jovem, antes mesmo de qualquer aproximação com o Design, Aloísio já demonstrava sua inclinação para as artes visuais.

Apesar de possuir trânsito no meio artístico, sua formação como artista foi autodidata e informal: ao ingressar na academia, em 1946, optou pela Faculdade de Direito, da Universidade do Recife. Segundo o próprio Aloísio Magalhães (Taborda \& Leite, 2003, p. 27), "quem é que não fazia direito naquela época? Era o primeiro sinal de bom senso, quer dizer, bom senso de desejo de uma projeção política, intelectual.... O que se viu, posteriormente, é que a faculdade de Direito reforçou ainda mais sua formação humanística e, por consequência, influenciou positivamente sua trajetória artística.

Aloísio graduou-se em Direito em 1950 e, um ano depois, teve uma marcante passagem pela Europa, como bolsista do governo francês, para estudar artes visuais. Apesar disso, retornou para Recife depois de dois anos, sem ter conseguido encontrar o que procurava. Em matéria publicada no jornal Última Hora, em março de 1952, ao ser questionado sobre o que gostaria ter encontrado em Paris, afirmou: "Mestres que me ensinassem o que não sei. Pensei que poderia trabalhar com alguns dos pintores que admiro, porém não foi possível. Inclusive no que diz respeito àqueles que, como Léger ${ }^{2}$ ou Lhote ${ }^{3}$, têm academia, não ensinam como eu entendo" (Taborda \& Leite, 2003, p. 35).

Em 1954, fundou - com Gastão de Holanda, Orlando da Costa Ferreira, José Laurenio de Melo, João Cabral de Melo Neto e Ariano Suassuna - uma gráfica experimental chamada "O Gráfico Amador": apesar de seus apenas sete anos de existência, a iniciativa foi de fundamental importância para as origens da tipografia moderna brasileira, e para diversas inovações em termos de ilustração, diagramação e impressão dos mais variados tipos de material gráfico (Funarte, 1982; Lima, 2014).

Além disso, Aloísio desenvolveu diversos outros trabalhos no campo das artes visuais, de pintura a escultura, passando pela gravura e desenho, tendo exposto seus trabalhos nos Estados Unidos e Europa. Magalhães sempre caracterizou sua produção artística por uma mescla de sofisticação intelectual e manifestação popular. Sua ligação com a cultura popular, estendeu-se por toda sua vida, tanto como artista, quanto como designer, culminando com influências percebidas ao longo da sua carreira política, em diversos cargos que ocupou no antigo Ministério da Educação e Cultura (MEC), chegando a ser nomeado Secretário Nacional de Cultura, em 1981 - um ano antes de sua morte.

$\infty<\infty<\infty<\infty<\infty<\infty<\infty<\infty<\infty<\infty<\infty<\infty$

2 Léger, Fernand (1881-1955). Pintor francês. [...] A influência de Léger sobre os artistas da época foi abrangente e diversificada. Há um museu com seu nome em Biot, na França. (Chilvens, 2001, p. 299)

3 Lhote, André (1885-1962). Pintor, escultor e teórico da arte francês. [...] Exerceu ampla influência sobre artistas mais jovens, tanto franceses como estrangeiros, através de sua própria academia de arte, a Académie Montparnasse, inaugurada em 1922. (Chilvens, 2001, p. 306) 


\section{Um designer forjado no seio da cultura popular}

Um fato marcante que interferiu em sua carreira artística e no Design ocorreu em 1956. Neste ano, Magalhães viajou para a América do Norte, desta vez com uma bolsa de estudos do Departamento de Estado dos Estados Unidos da América (EUA). Diferente do período em que esteve na Europa, sua estada nos EUA foi bastante frutífera, por ter realizado algumas exposições de seus trabalhos mas, acima de tudo, por ter propiciado seu encontro com Eugene Feldman, um artista gráfico e impressor. Feldman lhe apresentou novas técnicas e tecnologias - como, por exemplo, a impressão em off-set - que viriam a transformar profundamente a maneira de pensar de Aloísio com relação às artes gráficas e, por consequência, às artes visuais e seus trabalhos n’O Gráfico Amador.

Durante os dois meses que passou na Filadélfia, Aloísio observou, criou e refletiu muito a respeito de seu trabalho. Por mais que estivesse em outro país, em uma cultura diferente, lecionando como professor convidado e, ao mesmo tempo, aprendendo, pensava o tempo todo no Brasil e em como aquilo que lá desenvolvia poderia ser aplicado em seu próprio país.

De volta à Recife, traz a ideia da tecnologia como possibilidade de uma nova prática na produção de peças gráficas. Nos Estados Unidos finalmente compreendeu que a tecnologia pode ser uma aliada, tanto do artista, quanto do designer. Passou a compreender a importância dos processos industriais e, porque não, do próprio desenho industrial. Todos esses novos conhecimentos, no entanto, não o afastaram de suas ligações com as raízes nas artes visuais e, acima de tudo, na cultura popular.

Alexandre Wollner, nome de destaque do Design moderno brasileiro e que, assim como Magalhães, teve participação de relevo no cenário artístico brasileiro na década de $1950^{4}$, em entrevista a André Stolarski ${ }^{5}$, estabeleceu uma comparação entre ambos. Wollner ressalta que ao contrário dele - que foi criado em São Paulo e teve sua formação em desenho industrial na Alemanha, na HfG-Ulm ${ }^{6}$ - Aloísio "foi criado no centro dessa cultura regional brasileira que é Pernambuco; ele viveu em torno dela" (STOLARSKI, 2005 p. 57).

A observação de Alexandre Wollner, guarda em si um dado relevante a respeito de Aloísio: enquanto outros artistas visuais, como o próprio Wollner foram estudar desenho industrial na Europa e de lá trouxeram uma forte influência em seu método de trabalho, Magalhães forjou sua carreira de designer a partir de sua vivência como artista visual inserido dentro de uma cultura popular regional bastante peculiar. Quando final-

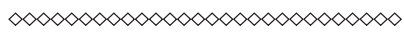

4 Alexandre Wollner estudou no Instituto de Arte Contemporânea (IAC), criado no Museu de Arte Assis Chateubriand de São Paulo (MASP). Posteriormente, interessado no movimento concretista, vinculou-se, em 1953, ao Grupo Ruptura, e apresentou suas obras construtivas na 2a Bienal Internacional de São Paulo. (Enciclopédia Itaú Cultural, 2016).

5 No livro "Alexandre Wollner e a formação do Design moderno no Brasil" (2005)

6 Abreviatura de Hochschule für Gestaltung Ulm (em português, Escola de Design de Ulm). 
mente fora estudar no exterior, este estudo não moldou Aloísio reduzindo-o a executor de um método específico. Pelo contrário, foi Aloísio Magalhães que selecionou aquilo que lhe era útil para aprimorar aquilo que ele já fazia, dentro de sua própria cultura e sua própria visão de mundo.

Embora tenha iniciado sua carreira de Design muito longe das preocupações empresariais - no seio do movimento O Gráfico Amador, em Recife - Aloísio atingiu o ápice dos seus esforços como designer durante as décadas de 1960 e 1970. [...]. Através da enorme repercussão atingida pela obra de Aloísio Magalhães, o designer brasileiro finalmente ingressava em um período de pleno potencial para realizações - e também contradições - característico do exercício da profissão no mundo multinacional (Denis, 2000, p. 166-167).

Na década de 1960, Aloísio Magalhães mudou-se para o Rio de Janeiro e funda o escritório $\mathrm{M}+\mathrm{N}+\mathrm{P}$ em conjunto com Luiz Fernando Noronha e Artur Lício Pontual. Posteriormente, o M+N+P transforma-se em AMPVDI (Aloísio Magalhães Programação Visual Desenho Industrial). Junto com seus novos sócios, Joaquim Redig e Rafael Rodrigues, atuou em diversos projetos de Design gráfico, tanto no âmbito da iniciativa privada, quanto para o setor público. Essa atuação como designer, no entanto, não afastou Aloísio das artes visuais: pelo contrário, pois nesse contexto que, no início dos anos 1970, Magalhães desenvolve um de seus mais impactantes trabalhos em artes visuais: o "cartema".

Atuando entre as artes visuais, então denominadas artes plásticas, e o Design, então chamado de desenho industrial, Magalhães conseguiu uma síntese, associando saberes de ambos os campos ou, como ele mesmo disse ${ }^{7}$, somando-os:

Por algum tempo, achei que a pintura estava morta. Hoje não posso dizer mais a mesma coisa. O desenho industrial me obrigou a ser mais pragmático, a ter um contato mais direto com o meu meio social, a aceitar muitos limites. Hoje, quando faço os cartemas, eu ainda estou aceitando um limite: o do cartão-postal. Mas, assim como não acredito que a pintura esteja morta, não coloco abaixo de nada do que faço minhas atividades como desenhista industrial. Acabei descobrindo que a cultura não é eliminatória, mas somatória.

$\infty<\infty<\infty<\infty<\infty<\infty<\infty<<<<<<<<<\infty<$

7 Publicado originalmente no Diário de Notícias, Rio de Janeiro, 17 de abril de 1974. Reproduzida em FUNARTE, 1982. 
Como pode ser observado, se a arte possibilita criação sem quaisquer demarcações, o Design propõe limites e, com eles, inevitavelmente a racionalidade que, às vezes, escapa à arte.

\section{Cartema}

Foi refletindo a respeito da produção das cédulas de cruzeiros por ele idealizadas, impressas pela Casa da Moeda brasileira, que Aloísio teve percepção de um fenômeno que foi o princípio de marcantes contribuições para o campo das artes visuais (ANJOS, 2002). A observação do efeito obtido pela impressão de várias cédulas em uma folha de papel maior foi fundamental para que Magalhães concebesse o que logo adiante seria batizado como "cartema". Neologismo criado pelo filólogo Antônio Houaiss, a palavra cartema designa uma composição visual construída a partir de várias cópias de determinada imagem, tendo como suporte a técnica da colagem.

Tais imagens eram, quase sempre, cartões postais convencionais, com retratos de paisagens, cenas cotidianas e fotografias diversas. Os postais eram colados lado a lado, em posições diferentes, dando ao conjunto uma nova unidade visual, face à continuidade das imagens montadas repetidamente em módulos simétricos, fortemente baseada na padronagem criada por esta composição vista como um todo.

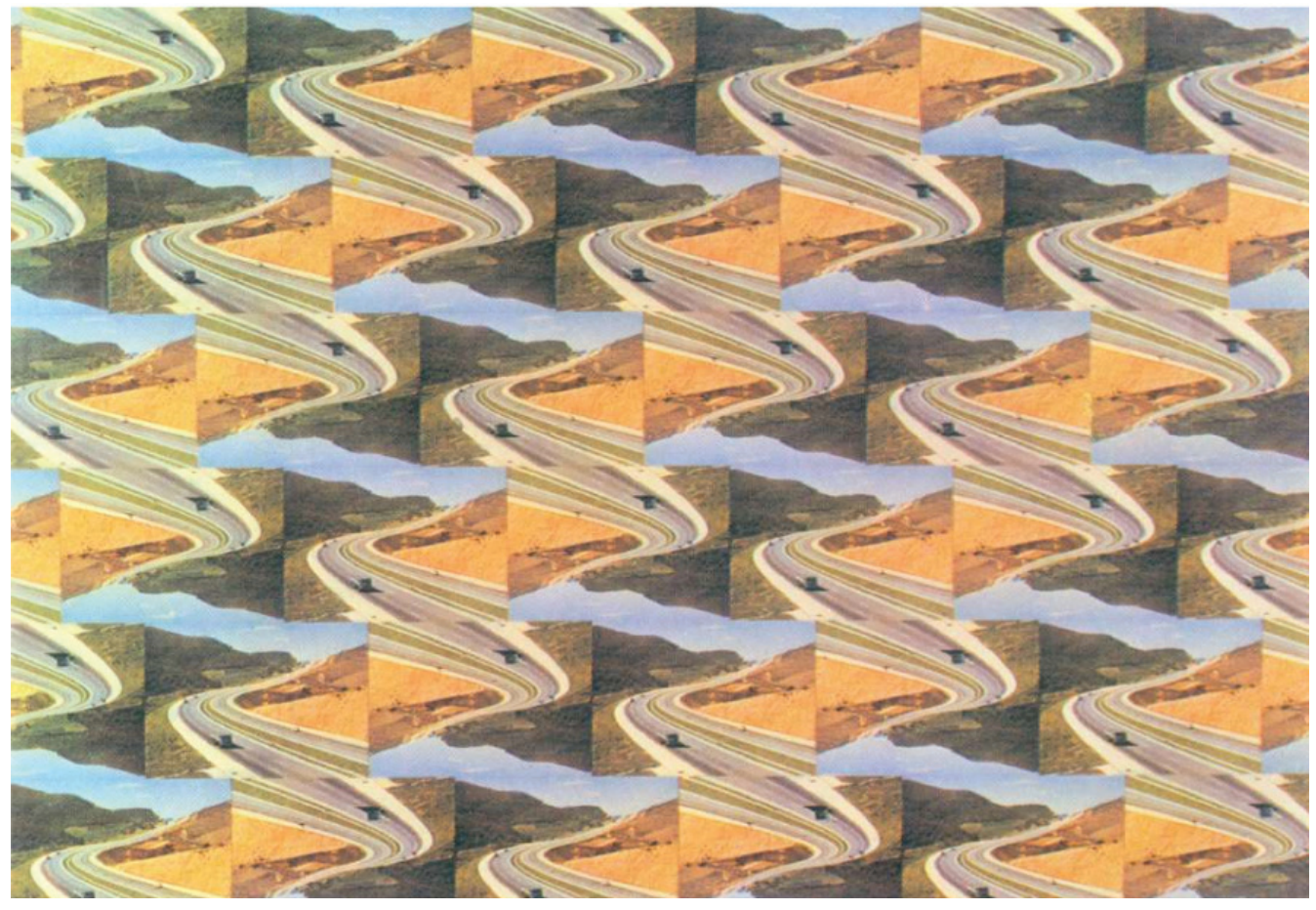

Fig. 1 - Um dos cartemas de Aloísio Magalhães, baseado em um cartão postal da Rodovia Castelo Branco, São Paulo (c. 1970) - Fonte: FUNARTE, 1982. 
A descrição não corresponde à potência da obra em si, pois pode levar a crer que existe algo de acidental ou, até mesmo, aleatório em sua criação. No entanto, Aloísio Magalhães (FUNARTE, 1982, p. 9) já afirmava que, "embora simples, o cartema não é um achado. Tem toda a vivência e o treinamento de um olho atento a tudo." Aí se reflete, uma vez mais, a síntese entre o intuitivo da arte e a racionalidade do design.

Aloísio, na mesma publicação, afirmava ainda, à época, que "a arte anda meio trágica, densa, sufocada. Perde diariamente o caráter lúdico e a graça. O cartema restitui ao espectador a alegria perdida. Ninguém fica indiferente". Ou seja, contextualizando a fala e a obra de Magalhães, é possível perceber que os cartemas surgiram num cenário artístico brasileiro no qual artistas buscavam uma relação mais participativa entre a obra e o público.

\begin{abstract}
Empenhado em tornar os cartemas uma proposição estética acessível a qualquer pessoa interessada - concretizando, dessa maneira, seu desejo de fazer da arte uma experiência coletiva -, Aloísio Magalhães divulgou, em catálogo de exposição, os procedimentos técnicos necessários a sua criação. Aproximava-se, de modo original, de propostas correntes na arte brasileira ao longo da década de 70, as quais buscavam a participação do público na criação de múltiplos (como Nelson Leirner), na ativação do sentido nas obras (Lygia Clark) ou mesmo em sua inserção em rotas alternativas de circulação artística (a arte postal, por exemplo) (ANJOS, 2002, p. 102).
\end{abstract}

Como proponente de uma iniciativa que buscava não apenas uma participação maior do público, com seus cartemas, Aloísio apropriou-se do ritmo e da repetição em uma linguagem acessível a todos e, sobretudo, encorajadora da participação do público interagindo e se engajando. Ainda nos anos 1970, Magalhães buscava questões que, ainda hoje, na arte contemporânea, seguem sendo relevantes: provocar a reflexão a respeito da experiência na qual está envolvido; focar na interação entre público e obra; e, também, propor um trabalho que seja, em última análise, uma construção coletiva.

Assim sendo, além de uma referência no Design, Aloísio Magalhães pode ser considerado um precursor da arte contemporânea.

\title{
Ritmo visual
}

"Tudo na vida é ritmo", disse Goethe ${ }^{8}$, mas ritmo sempre nos remete à música. Segundo HOUAISS (2001), ritmo é uma "sucessão de tempos fortes e fracos que se al-

$\infty<\infty<\infty<\infty<\infty<\infty<\infty<\infty<\infty<\infty<\infty<$

8 DUARTE, Jr. João Francisco. Fundamentos estéticos da educação. Campinas, 1998, p. 26. 
ternam com intervalos regulares em um verso, em uma frase musical etc."; esta é a primeira acepção, que se utiliza dos conceitos de sucessão, tempo, alternância, intervalos; quanto a tempo, usa "fortes" e "fracos", o que remete a sonoridade, verbal ou musical, limitando o conceito e excluindo o ritmo visual, a não ser que "forte" e "fraco" fossem considerados metaforicamente. A seguir, apresenta o dicionário três outras possibilidades semânticas, todas ligadas à música: "unidade abstrata de medida do tempo, a partir da qual são determinadas as relações rítmicas; pulsação, cadência”; "ocorrência de uma duração sonora em uma série de intervalos regulares"; "padrão rítmico que define um gênero; balanço, toque”. Na continuidade, apresenta o termo na acepção da retórica: "efeito causado no discurso pela repetição ordenada de elementos de ordem prosódica, principalmente de entoação, pausas, quantidade de sílabas, aliteração e acento tônico." Adiante, na literatura: "na arte literária, especialmente na poesia, o efeito estético ocasionado pela ocorrência de unidades melódicas, dispostas numa sequência contínua”.

Mas, é nas derivações por extensão de sentido que encontramos uma ampliação do conceito de ritmo, como seria lógico; um desses conceitos é "sequência harmônica de um fenômeno artístico, uma atividade, uma obra etc., no espaço e/ou no tempo”, exemplificando com ritmos da coreografia na dança, do cinema e de um espetáculo cênico. Por analogia, Houaiss apresenta, lembrando as ondas do mar e a batida do coração, que se trata de "movimento regular e periódico no curso de qualquer processo; cadência".

$\mathrm{Na}$ Biologia e na Ecologia, ritmo é uma "série de fenômenos biológicos que ocorrem com periodicidade, a intervalos regulares em um indivíduo ou nos organismos de uma espécie". E na Medicina, ritmo é uma "sequência regular de dois estados diferentes ou opostos, esp. (sic) no que diz respeito ao padrão dos batimentos cardíacos”. E por último, tomando como exemplos ritmos do cotidiano, como o dos estados ou da rapidez com que as coisas acontecem, freneticamente, na vida do dia-a-dia, o dicionário traz como derivação por metáfora, mais uma definição: "sucessão de situações ou atividades que constituem um conjunto fluente e homogêneo no tempo, ainda que não se processem com regularidade".

Esta acepção assemelha o conceito de ritmo ao de velocidade e reitera a polissemia do ritmo, no que se refere às possibilidades de constituir-se tanto no espaço como no tempo.

Décio Pignatari (2004, p. 21), por seu turno, define ritmo como "um ícone que resulta da divisão e distribuição no tempo e no espaço - ou no tempo-espaço - de elementos ou eventos verbovocovisuais (= verbais, vocais, visuais)". Ao citar a divisão ou distribuição de elementos (no caso dos cartemas, elementos visuais) no tempo e no espaço, mesmo sem qualquer análise formal mais aprofundada das combinações que ali se formam, é possível visualizar o ritmo visual provocado por esta organização espacial dos diversos exemplares de um mesmo cartão postal. Semelhante a uma parede de tijolos, nos cartemas os postais são rigidamente alinhados em intervalos pré-determinados.

Além de Pignatari (2004), autores oriundos de variadas correntes teóricas, tratam do tema e apresentam diferentes concepções e conceitos. Rabaça e Barbosa (1978), 
apresentam o ritmo como um dos requisitos ou qualidades que caracterizam, de forma semelhante, os diversos tipos de discursos. Para estes autores (1978, p. 397), o ritmo é a "sucessão adequada, no tempo ou no espaço de uma narração, dos diversos 'momentos' que apresentam variações de intensidade, de emoção, de velocidade no raciocínio, pausas, etc." . É importante ressaltar que, mesmo não se tratando de um texto verbal, um cartema apresenta preocupações relativas à sucessão adequada, no tempo e no espaço, redundando em uma conceituação semelhante àquela apresentada por Décio Pignatari. Por seu turno, as teóricas do Design Visual, Hellen Lupton e Jennifer Cole Phillips, dedicam um capítulo de seu livro "Novos Fundamentos do Design" (2008) para tratar deste assunto demonstrando, através de exemplos, a importância do ritmo no Design. Segundo as autoras,

O ritmo é um padrão forte, constante e repetido: o toque dos tambores, o cair da chuva, os passos no chão. Um discurso, uma música, uma dança, todos empregam o ritmo para expressar uma forma no tempo. Designers gráficos usam o ritmo na construção de imagens estáticas, bem como em livros, revistas e imagens animadas que possuam uma duração e uma sequência [...] A maioria das formas no Design busca ritmos que são pontuados por mudanças e variações (LUPTON \& PHILLIPS, 2008, p. 29).

Ao tratarem o ritmo como um 'padrão forte, constante e repetido', as autoras aproximam o conceito de ritmo ainda mais dos cartemas, pois inegável é o fato de que sua construção, baseada em uma rígida justaposição de cartões postais, gera tal padrão.

Ao buscar o conceito de ritmo na semiótica encontra-se em Greimas \& Courtés (2011, p. 423) que "o ritmo pode ser definido como uma espera, ou seja, como a temporalização, conseguida, conseguida mediante a aspectualidade incoativa, da modalidade do querer-ser, aplicada no intervalo recorrente entre agrupamentos de elementos assimétricos, que reproduzem a mesma formação". É possível identificar o que Greimas e Courtés apresentam como ritmo, nos cartemas de Aloísio Magalhães, pois as imagens quase abstratas, criadas através da justaposição dos cartões postais, são geradas justamente pelos intervalos recorrentes entre os agrupamentos destes cartões - elementos assimétricos - na composição final.

No ritmo visual, parecem operar ao menos dois componentes: a periodicidade, que implica a repetição dos elementos ou grupos de elementos, e a estruturação, que constitui o modo de organização destas estruturas na composição (SCÓZ \& RAMALHO E OLIVEIRA, 2010, p. 84). 
Assim, uma possível maneira de detectar a presença do ritmo visual em determinada imagem passa pela identificação dos componentes periodicidade e estruturação, segundo os autores, o que pode ser observado. Não é o objetivo deste artigo o estudo do ritmo visual mas os conceitos aqui apresentados pretendem mostrar a presença do ritmo visual na concepção dos cartemas, pois analisar um cartema de Aloísio Magalhães sem levar em conta as questões relacionadas ao ritmo visual seria omitir uma de suas principais características e potencialidades. Do mesmo modo, pretende-se ressaltar sua importância na elaboração e leitura do cartema, bem como mostrar de que forma é possível identifica-lo ao realizar uma leitura de imagem.

\section{Identificando o ritmo visual em um cartema, a partir da leitura formal da ima- gem}

Embora existam diferenças entre os diversos cartemas produzidos pelo artista Aloísio Magalhães, ao longo da década de 1970, entre eles há muitas semelhanças, principalmente no que tange ao ritmo visual, elemento compositivo dos cartemas escolhidos para serem abordado neste texto.

Desta forma, para fins de análise neste trabalho, foi escolhido um cartema da série "cartemas brasileiros" de 1972. Este cartema foi escolhido dentre os demais para compor uma série de lâminas que apresentam uma visão panorâmica do trabalho de Aloísio Magalhães no material distribuído na exposição Ocupação Aloísio Magalhães, ocorrida entre os dias 26 de julho e 24 de agosto, no Centro Itaú Cultural, em São Paulo.

Para embasar a leitura da imagem escolhida utilizou-se neste estudo, a proposta de Ramalho e Oliveira (2005), com base em fundamentos semióticos. É necessária a ressalva de que a proposta aborda e sugere uma leitura mais abrangente do que a leitura formal aqui procedida, uma vez que neste caso específico, foi abreviada, tendo em vista do foco deste estudo.

Em um primeiro momento, em função do contraste entre as cores de sua composição, identificam-se faixas diagonais mais claras, em um tom próximo do rosado, sobre um fundo predominantemente azul. Emoldurando as faixas mais claras diagonais, surgem triângulos de cor mais escura, que acabam por reforçar este mesmo contraste entre as faixas e o fundo. Neste ponto da leitura, ao definir tais linhas diagonais, determinamos o que Ramalho e Oliveira (2005, p. 49) chama de "macroestrutura da imagem visual".

Já neste ponto da leitura é identificável a presença do ritmo, na forma de um "padrão forte, constante e repetido", conforme apontam Lupton \& Phillips (2008, p. 29). No entanto, basta um olhar mais atento para que se perceba que o ritmo visual se apresenta através de diversas outras maneiras, no múltiplo de Aloísio. Ramalho e Oliveira (2005, p. 50) sugere que o passo seguinte para uma leitura de imagem seja a identificação dos "elementos constitutivos, tais como linhas, pontos, cores, planos, formas cor, luz, dimensão, volume e textura”. 


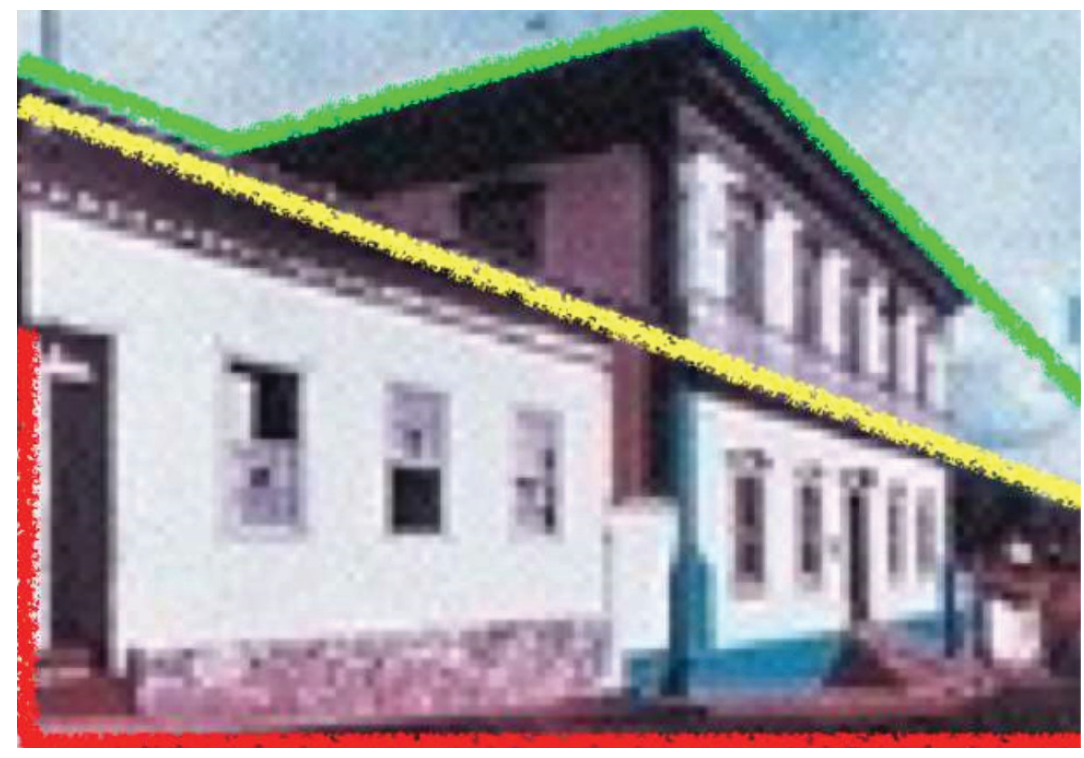

Fig. 5 - O módulo básico da composição de Aloisio Magalhães, um cartão postal que reproduz um casario colonial brasileiro e as linhas principais que, no conjunto, criaram as linhas principais assinaladas nas imagens da Fig. 4.

Fonte: Elaborado pelos autores, sobre OCUPAÇÃO Aloísio Magalhães, 2014

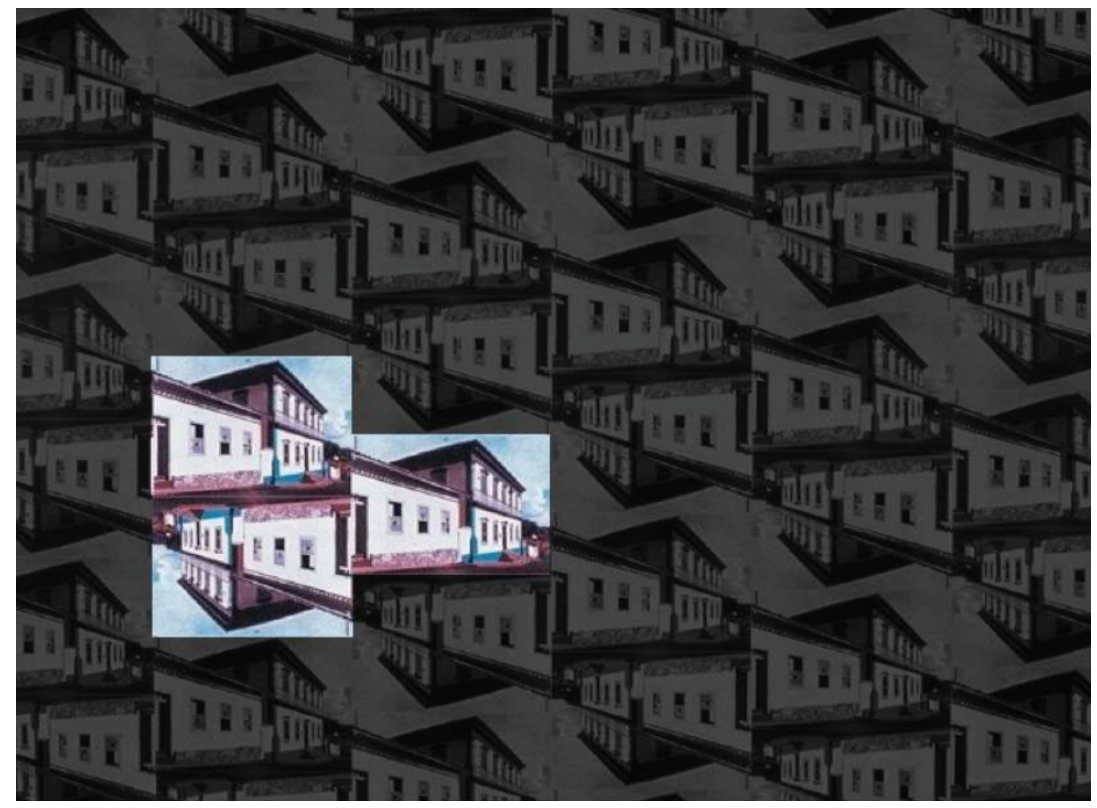

Fig. 6 - O módulo básico repetido três vezes, na justaposição que gera a composição final. Fonte: Elaborado pelos autores, sobre OCUPAÇÃO Aloísio Magalhães, 2014 


\section{Consideraç̧ões Finais}

Apesar de largamente reconhecido no meio do Design (ou Desenho Industrial) brasileiro como um de seus pioneiros, responsável por importantes trabalhos na área da identidade visual corporativa, bem como pela implantação do primeiro curso superior em Desenho Industrial no Brasil, Aloísio Magalhães deixou, também, como seu legado, colaborações relevantes no campo das artes visuais. Dentre tais colaborações, este trabalho analisou um de seus cartemas - um dos múltiplos realizados por Aloísio com cartões-postais, a partir de 1970. Este estudo teve como foco principal o ritmo visual presente em determinado cartema, a título de exemplo, uma vez que o ritmo é fundamento estético-visual gerador da dinâmica e da estesia provocadas pelos cartemas.

Como forma de destacar o conceito de ritmo visual e de que maneira ele é entendido em diferentes áreas do conhecimento - tais como Comunicação, Semiótica, Artes Visuais e Design -, em um primeiro momento este trabalho buscou diferentes conceitos oriundos de bases teóricas distintas, sem, no entanto, tentar esgotar o fenômeno. Buscou-se, prioritariamente, levantar de que maneira tais conceitos se interseccionam, bem como o ritmo visual pode ser identificado em uma imagem qualquer usando-se o cartema apenas como referência.

Em um segundo momento, foi realizada uma análise formal sintética com o objetivo de identificar a macroestrutura da imagem visual e, posteriormente, um levantamento de seus elementos constitutivos, para se averiguar a existência dos componentes periodicidade e estruturação, conforme apontados por Scóz \& Ramalho e Oliveira (2010). O resultado da análise formal mostrou o que já era esperado: o ritmo visual permeia intrinsecamente o próprio conceito de cartema de Aloísio Magalhães.

A partir da premissa de que "o ritmo visual se insere na produção das mais distintas sociedades, independentes de origens, natureza ou época” (SCÓZ \& RAMALHO E OLIVEIRA, 2010, p. 77), é possível compreender o uso do ritmo visual nos cartemas como um facilitador da fruição, bem como um detonador de reflexões múltiplas sobre a visualidade, o ser/estar no mundo, o ritmo da vida e mesmo sobre o "ser ou não ser".

Observar - ou fruir, ou ler, ou analisar, etc. - a cena, cotidiana, idealizada ou sonhada, de ponta-cabeça, da direita ou da esquerda, ou de todos esses ângulos ao mesmo tempo, nos remete à noção de que não há um só ângulo de visão válido na vida, nem um único ponto de vista: não há uma única verdade.

A ludicidade proposta pelo jogo para descobrir onde está a matriz do cartema, assim como a proposição estética que pode propiciar prazer por se sentir seguro ao se encontrar, a cada centímetro, no escaneamento da imagem, formas que se repetem, não omitem nem ignoram provocações filosóficas acerca do duplo, da ilusão e, principalmente, das inúmeras possibilidades existentes para se ver e perceber algo ou alguém. 


\section{Referências bibliográficas}

ANJOS, M. Coleções de sentidos. In: CHIARELLI, T. apropriações | coleções: catálogo da exposição. Porto Alegre: Santander Cultural. 2002.

CHILVENS, I. Dicionário Oxford de Arte. 2a ${ }^{\text {a }}$ Ed. São Paulo: Martins Fontes, 2001.

DENIS, R. C. Uma introdução à história do Design. São Paulo: Edgard Blücher, 2000.

ENCICLOPÉDIA ITAÚ CULTURAL de Artes Visuais. Disponível em: < http://www. itaucultural.org.br >. Acesso em: abr. 2016.

ESDI. Escola Superior de Desenho Industrial. Universidade do Estado do Rio de Janeiro. Disponível em: < http://www.esdi.uerj.br >. Acesso em: abr. 2016

FUNARTE. Cartemas: A Fotografia como Suporte de Criação. Rio de Janeiro: Fundação Nacional de Arte/Núcleo de Fotografia, 1982.

GREIMAS, A. J.; COURTÉS, J. Dicionário de Semiótica. São Paulo: Contexto, 2011.

HOUAISS, A. Cartemas. In: FUNARTE. Cartemas: A Fotografia como Suporte de Criação. Rio de Janeiro: Fundação Nacional de Arte/Núcleo de Fotografia, 1982.

. Dicionário Houaiss da Língua Portuguesa. Rio de Janeiro, Ed. Objetiva, 2001.

LIMA, G. C. O Gráfico Amador. Rio de Janeiro: Verso Brasil Ed, 2014.

LUPTON, E.; PHILlIPS, J. C. Novos fundamentos do Design. São Paulo: Cosac Naify, 2008.

MAGALHÃES, A. E Triunfo? A Questão dos Bens Culturais no Brasil. Rio de Janeiro: Nova Fronteira; Fundação Roberto Marinho, 1997.

OCUPAÇÃO Aloisio Magalhães. São Paulo: Itaú Cultural, 2014. 64 p. Catálogo de exposição, de 26 de julho a 24 de agosto de 2014, Itaú Cultural São Paulo.

PIETROFORTE, A. V. Semiótica visual: os percursos do olhar. São Paulo: Contexto, 2004.

PIGNATARI, D. O que é comunicação poética. Cotia, SP: Ateliê Editorial, 2004.

PRESIDÊNCIA DA REPÚBLICA. Decreto de 19 de outubro de 1998. Disponível em: $<$ http://www.planalto.gov.br/ccivil_03/dnn/Anterior\%20a\%202000/1998/Dnn7508. htm>. Acesso em: abr. 2016.

RACHAÇA, C. A.; BARBOSA, G. Dicionário de Comunicação. Com a colaboração de Muniz Sodré. Rio de Janeiro: Ed. Codecri, 1978.

RAMALHO E OLIVEIRA, S. R. Imagem também se lê. São Paulo: Ed. Rosari, 2005. 
SCÓZ, M.; RAMALHO E OLIVEIRA, S. R. Questões acerca do ritmo visual. In: FREITAS, N. K.; RAMALHO E OLIVEIRA, S. R. Variantes na visualidade. Florianópolis: Ed. da UDESC, 2010.

STOLARSKI, A. Alexandre Wollner e a formação do Design moderno no Brasil: depoimentos sobre o Design visual brasileiro. São Paulo: Cosac Naify, 2005.

TABORDA, F.; LEITE, J. S. A Herança do Olhar: o Design de Aloisio Magalhães. Rio de Janeiro: Artviva/SENAC. 2003. 